\title{
Comparison between the Modified Star Excursion Balance Test and the Traditional Star Excursion Balance Test in Recreational Athletes
}

\author{
Shaun Reghabi ${ }^{1}$, Lauren Power ${ }^{1}$, Keun Ok An ${ }^{2 *}$, Jupil Ko ${ }^{1}$ \\ ${ }^{\prime}$ Northern Arizona University, Phoenix, United States \\ ${ }^{2}$ Korea National University of Transportation, Chungju, Republic of Korea
}

Received: June 19, 2018

Accepted: July 3, 2018

Published online: July 31, 2018

Keywords:

Balance

Functional performance test

Postural control

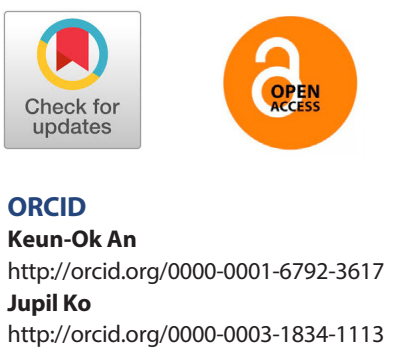

\begin{abstract}
OBJECTIVES To determine whether any difference exist between reach distance performance for the anterior (AN), posteromedial (PM), and posterolateral (PL) reach directions of the SEBT and the modified SEBT (mSEBT).

METHODS Twelve participants were recruited in the study (5 males, 7 females; age: $24.1 \pm 2.1 \mathrm{yrs}$; height: $175.5 \pm 5.3 \mathrm{~cm}$; mass: $70.3 \pm 15.1 \mathrm{~kg}$ ). The average of the 3 reach trials in each direction on each leg on both tests were calculated. Data was collected after 6 practice trials in each direction on both tests. Paired Samples t-tests were performed to compare the normalized reach distances between the SEBT and mSEBT. Normalized values were calculated as a percentage of mean reach distance to a participant's limb-length. RESULTS For the normalized reach distances, both sides of the PM and PL reach directions showed a statistically significant difference between the SEBT and mSEBT $(p<.05)$. There was no statistical significant difference between the tests in the AN (right $[p=.203]$; left $[p=.357]$ ) reach directions.

CONCLUSIONS Differences in reach distance performance were only found in both sides of the PM and PL directions between the SEBT and mSEBT. These findings may indicate that the unstable surface may lead to an increase in the difficulty of testing. Clinicians may consider to utilize the MSEBT to assess dynamic postural control in physically active young adult population. Further research is required with the use of physically active young adult population.
\end{abstract}

(c) The Asian Society of Kinesiology and the Korean Academy of Kinesiology

\section{Introduction}

Functional dynamic tests such as the Star Excursion Balance Test (SEBT) is often used as a tool to assess dynamic postural control and help predict athletes at a greater risk for lower extremity injuries [1-3]. In order to perform the SEBT, a blend of strength, balance, proprioception, and flexibility (range of mo-

*Correspondence: Keun Ok An, Korea National University of Transportation, 50 Daehak-ro, Chungju-si, Chungbuk, Republic of Korea.

E-mail:koan@ut.ac.kr tion) is required [3]. The main objective of the SEBT is to maintain both a single limb stance on one leg while simultaneously reaching as far as possible with the contralateral leg in a specific direction. The SEBT originally incorporated reaching in eight different directions, but it was found that three reach directions (anterior, posteromedial, and posterolateral) were predictive of lower extremity injury [3]. The SEBT shows an intrarater reliability of moderate to good with an intraclass correlation (ICC) ranging from .67 to .97 [2]. The main advantage of the SEBT is its ability to be an inexpensive quick method, which can be easily set up with the use of white athletic tape and/or measuring 
tape on any stable flat surface $[2,3]$.

Dynamic balance performance has previously been linked with increased injury risk in a diverse array of populations $[3,4]$. While the SEBT is a popular functional dynamic test to measure the dynamic postural control of an athlete [5], more challenging conditions are often required to distinguish between healthy individuals and individuals with balance deficits [3]. Highly balanced populations, such as gymnastic athletes and competitive divers, who perform the SEBT may do so easier than their non-highly balanced counterparts. One quick and simple solution to increase the difficulty of a balance task and to allow greater distinction is the use of a foam pad as an unstable surface [6,7]. Therefore, the purpose of this study is to examine the relationship between the modified star excursion balance test (mSEBT) and the SEBT.

We hypothesized that a recreationally active population would have lower bilateral reach distances with the mSEBT as compared to the bilateral reach distances on the SEBT.

\section{Methods}

\section{Participants}

A total of twelve recreational athletes were recruited in the study (5 males, 7 females; age: $24.1 \pm 2.1$ yrs; height: $175.5 \pm$ $5.3 \mathrm{~cm}$; mass: $70.3 \pm 15.1 \mathrm{~kg}$ ). We defined recreational athlete as any person who partakes in physical activity, such as running, walking, lifting weights, or playing sports in intramural sports teams for at least 90 min per week $[8,9]$.

The inclusion criteria that determined the participant's' eligibility included being between 18 to 25 years of age and participated in a recreational activity as defined above. Prior to the study the participants received and completed a Lower Extremity Health History Questionnaire [10]. The Lower Extremity Health History Questionnaire is a 7 question self-assessment that allows the participants to be eligible based on the exclusion criteria. Exclusion criteria included: previous history of surgery or fracture to their lower extremity, current injury to their lower extremity, pregnancy, any vestibular disorders, Charcot-Marie-Tooth disorder, or Ehlers-Danlos disorder [11]. Participants that did not meet the criteria were automatically disqualified from this study.

\section{Procedures}

A single testing session of 30 minutes was scheduled in an athletic training laboratory. Upon arrival for the testing session, each participant was informed and familiarized with the testing procedures. The procedures of this research involved performing three reach directions (anterior [AN], posteromedial $[\mathrm{PM}]$, and posterolateral $[\mathrm{PL}])$ on a stable surface for the SEBT and an unstable surface (Balance-pad, AIREX $^{\circledast}$, Sins, SWI) for the mSEBT. All testing and data collection was conducted by a single investigator. Each participant signed an informed consent document, which had already been approved by the University's Institutional Review Board (ID\#:1026922-3), which also approved the study being conducted.

Prior to the start of testing, participant's demographic information was recorded including height, mass, gender, and dominant side of the limb. Participants' individual limblength was also recorded, from the anterior superior iliac spine (ASIS) to the most distal portion of the medial malleolus with a cloth measuring tape [12]. Participants viewed an instructional video, created by the researchers, demonstrating the test and testing procedures. The instructional video included both specific directions of the test along with a visual demonstration of the test itself and errors that constitute a discarded trial.

The video instructed and showed the participant to stand on a single leg in the center of a grid, with the most distal aspect of the great toe at the starting line [13]. While maintaining both a single-leg stance and hands on the hips, the participant was instructed and shown to reach with the free limb in AN, PM, and PL directions in relation to the single limb stance foot. The participant was instructed and shown to go through the 3 directions of the trials in a counterclockwise fashion, starting with the AN direction [13]. The video stated and showed the participant, that a trial was discarded and repeated if the participant (1) failed to maintain unilateral stance, (2) lifted or moved the stance foot from the grid, (3) touched down with the reach foot, or (4) failed to return the reach foot to the starting position (5) released hands from hips at any point in time during reach [13]. The video repeated outlining the same instructions while standing on the 
Table 1. Performance on the SEBT and mSEBT

\begin{tabular}{|c|c|c|c|c|c|}
\hline \multirow[b]{2}{*}{ Reach Direction } & \multirow[b]{2}{*}{ Participant Limb } & \multicolumn{2}{|c|}{ Test (\%) } & \multirow[b]{2}{*}{ p-value } & \multirow[b]{2}{*}{ Cohen's o } \\
\hline & & SEBT & mSEBT & & \\
\hline \multirow{2}{*}{ AN } & Right & $65.78 \pm 2.56$ & $62.70 \pm 1.73$ & .203 & .39 \\
\hline & Left & $65.87 \pm 2.75$ & $112.40 \pm 49.16$ & .357 & -.28 \\
\hline \multirow{2}{*}{ PM } & Right & $98.18 \pm 2.69$ & $93.22 \pm 3.48$ & $.032^{*}$ & .71 \\
\hline & Left & $97.43 \pm 3.38$ & $90.18 \pm 4.30$ & $.008^{*}$ & .92 \\
\hline \multirow{2}{*}{ PL } & Right & $91.41 \pm 3.04$ & $83.43 \pm 3.612$ & $.001^{*}$ & 1.29 \\
\hline & Left & $91.75 \pm 3.40$ & $87.10 \pm 3.66$ & $.019^{*}$ & .79 \\
\hline \multicolumn{6}{|c|}{ *Significantly different $(p<0.05)$} \\
\hline \multicolumn{6}{|c|}{$\mathrm{AN}=$ Anterior $; \mathrm{PM}=$ Posteromedial $; \mathrm{PL}=$ Posterolateral } \\
\hline \multicolumn{6}{|c|}{ SEBT $=$ Star Excursion Balance Test } \\
\hline mSEBT $=$ Modified Sta & on Balance Test & & & & \\
\hline
\end{tabular}

opposite leg and for both limbs with the modified test.

Due to a significant learning effect that yields the greatest reach distance measured, participants were given 6 practice trials on each leg in each of the 3 reach directions prior to the final recorded trials $[14,15]$. With careful observation of the researcher the maximal reach distance was marked with an erasable utensil on the tape at the point where the most distal part of the foot reached. The distance between the starting line and this point was then measured by a cloth measuring tape [13]. The greatest of 3 trials was recorded for each reach direction and averaged for both the SEBT and mSEBT.

\section{Statistical Analysis}

For this cross-sectional study, SPSS ${ }^{\circledast}$ (version 24.0; IBM Corporation $($, Armonk, NY) statistical software was used to analyze the data. Prior to analysis, mean reach distances were normalized to the participant's limb-length [16]. Normalization was performed by dividing each mean reach distance by a participant's leg length, and then by multiplying by 100 [13]. Making each normalized value a percentage of mean reach distance to a participant's limb-length. In order to compare mean reach distances between the SEBT and the mSEBT, we used a Paired Samples t Test. The independent variable of this research is the participant's reach distances on both the SEBT and the mSEBT. The dependent variable is whether the SEBT was modified or not. By means of the Paired Samples $t$ Test $(\mathrm{p}<.05)$, we were able to measure the difference between our hypothesis and the true findings of this study.

\section{Results}

Means, standard deviations, $\mathrm{p}$-value's, and effect size (Cohen's d) for both tests on each side of the AN, PM, and PL reach directions were reported in Table 1. For the normalized reach distances, both sides of the PM and PL reach directions showed a statistically significant difference between the SEBT and mSEBT $(\mathrm{p}<.05)$. There was no statistical significant difference between the tests in the AN (right [p = .203]; left $[\mathrm{p}=.357])$ reach directions.

\section{Discussion}

Current literature supports using the SEBT as a way to help predict lower extremity injury risk as well as discovering conditions, such as chronic ankle instability [3,17]. The AN, PM, and PL show to be the best directions that are most indicative of a balanced deficit without being repetitive [17]. Since a poor performance on the SEBT in these three directions has been shown to have an increase lower extremity in- 
jury risk $[1,3,5]$. Populations who already have a higher level of balance may find this functional test easy therefore, not creating reliable scores for this population on this specific test [18]. So, the mSEBT was developed to increase difficulty in these three directions for those populations who are highly balanced, such as gymnasts, divers, ice skaters, skiers, and surfers.

The main purpose of this study was to determine any differences in reach distances between the SEBT and mSEBT. Our results indicated that both sides of the PM and PL reach directions were the only directions to show a difference between the two tests. Our findings contradict with Coughlan et al [19], who reported that participants reached farther in the AN direction on the SEBT than on the Y Balance TestTM (YBT) with no observed differences in the PM and PL directions. The YBT is a lower extremity test that is similar to both the mSEBT, in the fact that both test in the AN, PM, and PL directions as well as being on an elevated surface. Further contrast to our findings, existing literature supports the use of measuring $\mathrm{AN}$ reach direction $[3,5]$. With no statistically significant difference in reach length, the mSEBT may not be a reliable measurement in the $\mathrm{AN}$ reach direction. The difference in levels of the elevated stance foot on the foam pad and the lower reach foot during the mSEBT compared with the flat level base for the SEBT may influence the individual's reach distances by being both physically challenging to the stance foot and being higher off the ground. This combination may explain the difference in reach distances in both the PM and PL directions.

The authors recognize there were several limitations of this study. The use of a small sample size of recreational athletes, twelve in total. Findings on our recreationally physical active population may not be transferable to physically active young adult population with increased balance, as they may test differently on the SEBT and mSEBT. The use of only one researcher on data collection of recording reach distances may have had an effect on overall accuracy of the collection. Also, participants' characteristics such as a total volume and type of physical activity should be reported in the future study.

\section{Conclusions}

Differences in reach distance were only observed in both sides of the PM and PL directions, with none noted in the AN direction, between the SEBT and mSEBT. The results of this study may indicate that the unstable surface may lead to an increase in the difficulty of testing. Clinicians may consider to utilize the mSEBT to assess dynamic postural control in physically active young adult population who excel at the SEBT. Further research is required with both a larger sample size and highly balanced populations.

\section{Conflicts of Interest}

The authors declare no conflict of interest.

\section{References}

1. Smith J, DePhillipo N, Kimura I, Kocher M, Hetzler R. Prospective functional performance testing and relationship to lower extremity injury incidence in adolescent sports participants. Int J Sports Phys Ther. 2017; 12(2):206-218.

2. Plisky PJ, Gorman PP, Butler RJ, Kiesel KB, Underwood FB, Elkins B. The reliability of an instrumented device for measuring components of the star excursion balance test. N Am J Sports Phys Ther. 2009; 4(2):92-99.

3. Plisky PJ, Rauh MJ, Kaminski TW, Underwood FB. Star excursion balance test as a predictor of lower extremity injury in high school basketball players. J Orthop Sports Phys Ther. 2006; 36(12):911-919.

4. Noronha MD, Franca LC, Haupenthal A, Nunes GS. Intrinsic predictive factors for ankle sprain in active university students: a prospective study. Scan J Med Sci Sports. 2013; 23(5):541-547.

5. Gribble PA, Hertel J, Plisky P. Using the star excursion balance test to assess dynamic postural-control deficits and outcomes in lower extremity injury: a literature and systematic review. J Athl Train. 2012; 47(3):339-357. 
6. Shumway-Cook A, Horak FB. Assessing the influence of sensory interaction of balance. Suggestion from the field. Phys Ther. 1986; 66(10):1548-1550.

7. Patel M, Fransson PA, Lush D, Gomez S. The effect of foam surface properties on postural stability assessment while standing. Gait and Posture. 2008; 28(4):649-656.

8. Ko J, Rosen AB, Brown CN. Comparison between single and combined clinical postural stability tests in individuals with and without Chronic Ankle Instability. Clin J Sport Med. 2017; 27(4):394-399.

9. Rosen AB, Ko J, Brown CN. Diagnostic accuracy of instrumented and manual talar tilt tests in chronic ankle instability populations. Scand J Med Sci Sports. 2014; 25(2):214-221.

10. Gregg EW, Sorlie P, Paulose-Ram R, et al. Prevalence of Lower-Extremity Disease in the U.S. Adult Population $\geq 40$ Years of Age With and Without Diabetes. 1999-2000 National Health and Nutrition Examination Survey. 2004; 27(7):1591-1597.

11. Gribble PA, Delahunt E, Bleakley CM, et al. Selection criteria for patients with chronic ankle instability in controlled research: a position statement of the international ankle consortium. J Athl Train. 2014; 49(1):121-127.

12. Jamaluddin $S$, Sulaiman AR, Imran MK, Juhara $H$, Ezane MA, Nordin S. Reliability and accuracy of the tape measurement method with a nearest reading of 5 $\mathrm{mm}$ in the assessment of leg length discrepancy. Sin- gapore Med J. 2011; 52(9):681-684.

13. Hyong IH, Kim JH. Test of intrarater and interrater reliability for the star excursion balance test. J Phys Ther Sci. 2014; 26(8):1139-1141.

14. Linek P, Sikora D, Wolny T, Saulicz E. Reliability and number of trials of $y$ balance test in adolescent athletes. Musculoskelet Sci Pract. 2017; 31:72-75.

15. Robinson RH, Gribble PA. Support for a reduction in the number of trials needed for the star excursion balance test. Arch Phys Med Rehabil. 2008; 89(2):364370.

16. Gribble PA, Hertel J. Considerations for normalizing measures of the star excursion balance test. Meas Phys Edu Ex Sci. 2003; 7(2):89-100.

17. Hertel J, Braham RA, Hale SA, Olmsted-Kramer LC. Simplifying the star excursion balance test: analyses of subjects with and without chronic ankle instability. J Orthop Sports Phys Ther. 2006; 36(3):131-137.

18. Hale SA, Hertel J, Olmsted-Kramer LC. The effect of a 4-week comprehensive rehabilitation program on postural-control and lower extremity function in individuals with chronic ankle instability. J Orthop Sports Phys Ther. 2007; 37(6):303-311.

19. Coughlan GF, Fullam K, Delahunt E, Gissane C, Caulfield BM, Sci M. A comparison between performance on selected directions of the star excursion balance test and the y balance test. J Athl Train. 2012; 47(4):366-371. 